\section{JTI}

JOURNAL OF

TRAUMA AND INJURY

\title{
Epidemiology of Facial Bone Fractures During the Coronavirus Disease 2019 Pandemic: A Single Korean Level I Trauma Center Study
}

\author{
Min Ji Kim, M.D., Ph.D., Kyung Min Yang, M.D., Hyoseob Lim, M.D., Ph.D. \\ Department of Plastic and Reconstructive Surgery, Ajou University School of Medicine, \\ Suwon, Korea
}

Received: December 1, 2021

Revised: December 8, 2021

Accepted: December 10, 2021

\section{Correspondence to}

Hyoseob Lim, M.D., Ph.D.

Department of Plastic and Reconstructive Surgery, Ajou University School of Med-

icine, 164 World cup-ro, Yeongtong-gu,

Suwon 16499, Korea

Tel: +82-31-219-5614

Fax: +82-31-219-5610

E-mail: h.lim@aumc.ac.kr

ORCID: https://orcid.org/0000-0002-

6251-8281

Purpose: The medical community has been heavily impacted by the coronavirus disease 2019 pandemic. The management of facial trauma patients has been affected by the patient capacity of emergency rooms. In this study, we share our experiences of facial trauma management during the social lockdown period and investigate the epidemiological changes in facial bone fractures.

Methods: A total of 997 patients who presented to Ajou University Hospital Emergency Center and were evaluated by plastic or maxillofacial surgeons for facial trauma were included in this retrospective study. Our study design was a comparative study of two groups: the 2019 group (control) and the 2020 group (the experimental group that experienced social lockdown).

Results: The total number of emergency room inpatients reflected the national pandemic trends with three peaks in patient numbers. According to these trends, facial bone fractures had two different low points in August 2020 and December 2020. A comparison of the 2019 and 2020 facial bone fractures did not show a statistically significant difference in the total number of patients. An analysis of the causes of trauma showed that domestic accidents increased in 2020 (30.92\%; $p<0.001)$. Among the anatomical sites of facial injury in surgical patients, the frontozygomatic complex fracture increased the most in 2020 ( $p=0.018$ ). Facial injuries with two separate sites of injury or with three or more involved sites also showed a significant increase in $2020(p<0.001)$.

Conclusions: We demonstrated that the incidence of facial trauma patients correlated with the incidence of patients presenting to the emergency department and that facial trauma is inextricably related to multi-trauma cases. Domestic accidents and facial trauma with multiple anatomically involved sites are increasing trends that need more attention.

Keywords: Trauma centers; Maxillofacial injuries; Epidemiology; COVID-19; Facial fracture 


\section{INTRODUCTION}

The World Health Organization officially declared the current outbreak of coronavirus disease 2019 (COVID-19) caused by severe acute respiratory syndrome coronavirus-2 (SARS-CoV-2) a pandemic in March 11, 2020 [1]. Unlike previous respiratory viral diseases, COVID-19, whether symptomatic or asymptomatic, is highly contagious [2]. The early stage of infection has a high number of viral droplets that are contained in patients' respiratory secretions. Simple conventional personal protection can prevent infection, and social distancing among people has been emphasized to prevent the spread of infection. Because of the rapid increase in the number of infected patients, social lockdowns were widely enforced to limit the spread of the etiological agent, SARS-CoV-2 [3].

The first large urban outbreak, outside of China, was a cluster of COVID-19 infections in Daegu, South Korea in February 2020 [4]. Once the first patient was identified in January, the number of infected patients rapidly increased to 909 in February. Thus, the government implemented a high-intensity social lockdown policy that did not permit students to go to school or people to leave home to go to work or restaurants. The first lockdown was provisional in March 2020; however, a stepwise lockdown policy has continued to remain in force from August 2020 until now. These continued policies have impacted many aspects of society.

The medical community has been greatly affected during the pandemic period. Many medical professionals have focused on the treatment of isolated patients with COVID-19 [5]. Only a limited number of medical teams have been able to operate emergency rooms for nonCOVID patients. The management of facial trauma cases is impacted by the patient capacity in emergency rooms. Reports from studies in this rapidly developing specialty indicate that maxillofacial injuries are increasing in frequency and severity, owing to the heavy dependence on road transportation and the increase in socioeconomic-related activities of populations in developing countries [6,7]. In particular, these factors have impacted level 1 trauma centers, resulting in significant changes. Ajou University Hospital has the largest national trauma center and more than $50 \%$ of the patients with facial

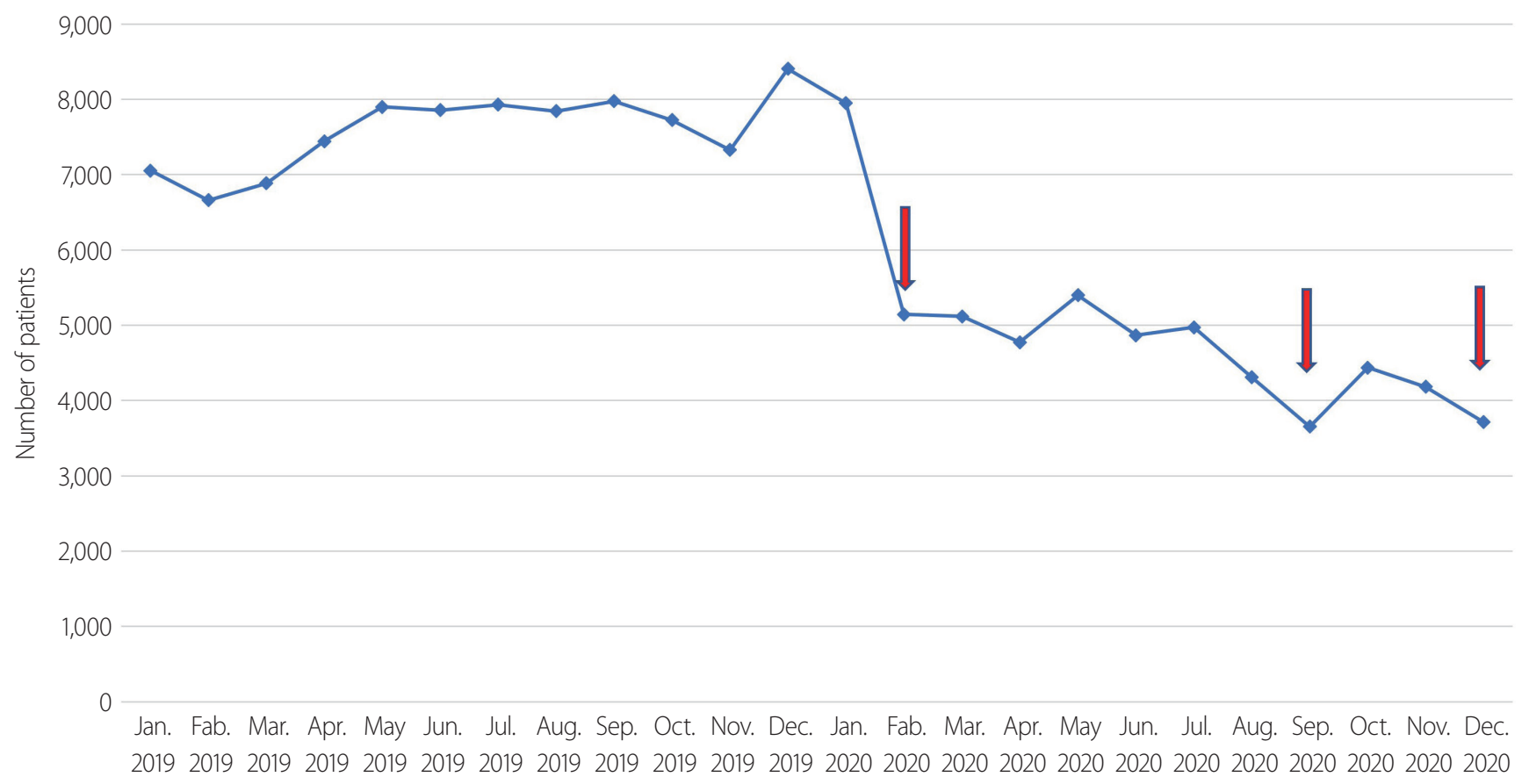

Fig. 1. Emergency room inpatient number trends from January 2019 to December 2020. Arrows indicate 1st, 2nd, and 3rd domestic coronavirus disease 2019 outbreak. 
injuries have multiple traumas, requiring coordinated management between emergency physicians and surgical specialists $[8,9]$. Despite strong relationship between level 1 trauma center and facial trauma patients, most studies have focused merely on the effect of high-impact disease outbreaks in trauma center.

In this study, we share our experiences of facial trauma management during the social lockdown period and present the results of an investigation of epidemiological changes in facial bone fractures. We also analyzed the impact of level 1 trauma center medical capacity on facial bone fracture case management during the pandemic period.

\section{METHODS}

This study was approved by the Institutional Review Board (IRB) of Ajou University College of Medicine
(IRB No. AJIRB-DEV-INT-21-167). The requirement for informed consent was waived by the IRB because of the retrospective study design. This retrospective study was based on a chart review of patients who presented to the emergency center of Ajou University Hospital in Suwon, South Korea, from January 1, 2019 to December 31, 2020.

This study included a total of 997 patients who presented to Ajou University Hospital Emergency Center and consulted with the plastic surgery, oral, or maxillofacial departments for facial bone fractures. Baseline patient information was collected, and the causes of injury were classified into seven categories: domestic accidents, physical violence, traffic accidents, sports-leisure injuries, work-related injuries, slip and fall injuries, and others. Domestic violence can be defined in a variety of ways and is associated with a variety of injuries, not limited to acute physical injuries. In this study, we classified injuries according to the physical location in which the injury occurred. Even if they occurred outdoors, non-sports-re-

Table 1. Monthly comparison of patients evaluated in the emergency room and patients who received a consult for facial bone fracture

\begin{tabular}{|c|c|c|c|c|c|c|c|c|c|c|}
\hline & & 20 & & & & 20 & & & Patient & Patient \\
\hline & $\begin{array}{c}\text { Facial bone } \\
\text { fracture }\end{array}$ & Total ER & Ratio $(\%)^{a}$ & ISS $>15$ & $\begin{array}{c}\text { Facial bone } \\
\text { fracture }\end{array}$ & Total ER & Ratio (\%) ${ }^{\mathrm{a}}$ & ISS $>15$ & $\begin{array}{l}\text { difference } \\
\text { 2020/2019 }\end{array}$ & $\begin{array}{l}\text { ference (\%) } \\
\text { 2020/2019 }\end{array}$ \\
\hline $\begin{array}{c}\text { Total number } \\
\text { of patients }\end{array}$ & $561(100.00)$ & & & 1,094 & $436(100.00)$ & & & 1,248 & & \\
\hline Jan. & $27(4.81)$ & 7,055 & 38.27 & 77 & 38 (8.72) & 7,949 & 47.80 & 78 & 11 & 40.74 \\
\hline Feb. & $27(4.81)$ & 6,660 & 40.54 & 63 & $27(6.19)$ & 5,144 & 52.49 & 90 & 0 & 0.00 \\
\hline Mar. & $39(6.95)$ & 6,885 & 56.64 & 83 & $37(8.49)$ & 5,118 & 72.29 & 79 & -2 & -5.13 \\
\hline Apr. & $43(7.66)$ & 7,446 & 57.75 & 80 & $39(8.94)$ & 4,773 & 81.71 & 102 & -4 & -9.30 \\
\hline May & $43(7.66)$ & 7,902 & 54.42 & 107 & 45 (10.32) & 5,400 & 83.33 & 102 & 2 & 4.65 \\
\hline Jun. & 47 (8.38) & 7,856 & 59.83 & 95 & $41(9.40)$ & 4,867 & 84.24 & 107 & -6 & -12.77 \\
\hline Jul. & $50(8.91)$ & 7,929 & 63.06 & 86 & $43(9.86)$ & 4,971 & 86.50 & 101 & -7 & -14.00 \\
\hline Aug. & $52(9.27)$ & 7,844 & 66.29 & 101 & $29(6.65)$ & 4,310 & 67.29 & 132 & -23 & -44.23 \\
\hline Sep. & $53(9.45)$ & 7,975 & 66.46 & 104 & $30(6.88)$ & 3,655 & 82.08 & 139 & -23 & -43.40 \\
\hline Oct. & $64(11.41)$ & 7,724 & 82.86 & 111 & $38(8.72)$ & 4,436 & 85.66 & 120 & -26 & -40.63 \\
\hline Nov. & $58(10.34)$ & 7,330 & 79.13 & 89 & $41(9.40)$ & 4,183 & 98.02 & 108 & -17 & -29.31 \\
\hline Dec. & $58(10.34)$ & 8,406 & 69.00 & 98 & $28(6.42)$ & 3,715 & 75.37 & 90 & -30 & -51.72 \\
\hline
\end{tabular}

Values are presented as number (\%). The score of ISS is based on Korean Trauma Data Bank (KTDB) data.

ISS: Injury Severity Score.

Ratio=facial bone fracture/total ER. 
lated injuries were classified in categories such as "slip and fall" or "other." Injuries were also evaluated based on their anatomical location.

Our study design was a comparative study of two different period groups, the 2019 and 2020 groups; the latter group experienced a social lockdown due to the COVID-19 pandemic. We analyzed the monthly epidemiological changes, reasons for the changes in trauma, and surgical management changes during the pandemic period.

Continuous variables were presented as means and standard deviations and were compared using the $t$-test. Categorical variables were presented as frequencies and percentages and were compared using the chi-square and Fisher exact tests. Statistical analyses were performed using SPSS version 19.0 (IBM Corp.; Armonk, NY, USA). Statistical significance was indicated by a $p$-value $<0.05$.

\section{RESULTS}

A total of 997 patients were included in this study, and 711 patients who were diagnosed with facial bone fractures and underwent surgery were evaluated. On January 20, 2020, the first COVID-19 patient was identified in Korea and the subsequent number of patients rapidly increased, with a peak on February 29, 2020 of 909 patients. The increased number of cases resulted in high-intensity social distancing with a city lockdown beginning in March 2020. The total number of emergency room inpatients reflected this trend (Fig. 1). The number of patients in January was 7,949 and steeply decreased to 5,144 patients in February, and 5,188 patients in March. The national high-intensity lockdown strategy remained in effect until August 2020. On August 27, Korea reported a second large outbreak with 441 patients, which led to a nationwide lockdown

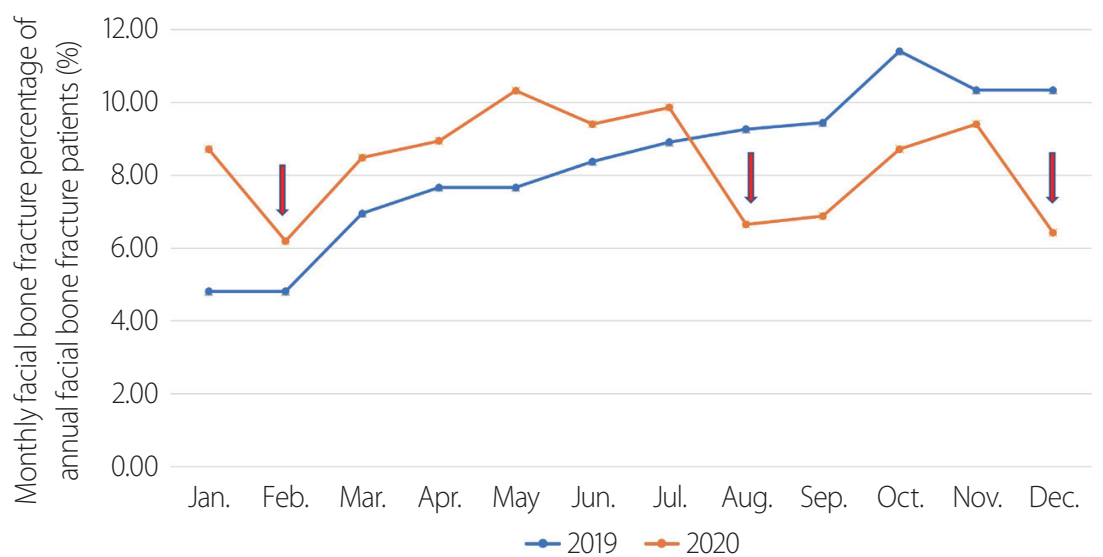

Fig. 2. Monthly facial bone fracture inpatient number trends in 2019 versus 2020. Arrows indicate 1st, 2nd, and 3rd domestic coronavirus disease 2019 outbreak.

Table 2. Comparison of causes of facial bone fracture: the control period (2019) versus the social lockdown period (2020)

\begin{tabular}{|c|c|c|c|c|}
\hline & 2019 & 2020 & Difference & $p$-value \\
\hline Domestic accident & $23(4.10)$ & 135 (30.92) & 112 (486.36) & $<0.001^{\mathrm{a}}$ \\
\hline Physical violence & $106(18.85)$ & $106(24.34)$ & $0(0.35)$ & $0.042^{\mathrm{a}}$ \\
\hline Traffic accident & $97(17.21)$ & $55(12.50)$ & $-42(-43.56)$ & $0.04^{\mathrm{a}}$ \\
\hline Sports-lesure & $64(11.48)$ & $29(6.58)$ & $-36(-55.44)$ & $0.009^{a}$ \\
\hline Industrial & $41(7.38)$ & $23(5.26)$ & $-18(-44.55)$ & 0.241 \\
\hline Slip and fall & $216(38.52)$ & $66(15.13)$ & $-150(-69.47)$ & $<0.001$ \\
\hline Others & $14(2.46)$ & $23(5.26)$ & $9(66.34)$ & $<0.001$ \\
\hline Total & $561(100.00)$ & $436(100.00)$ & $-125(-22.28)$ & \\
\hline
\end{tabular}

Values are presented as number (\%).

astatistically significant $p<0.05$. 
and second-level social distancing in metropolitan areas. A third outbreak was reported on December 25, with 1,240 patients. Thus, there were two more points in $\mathrm{Au}$ - gust and December with decreases in trauma cases due to the pandemic-related lockdown (Fig. 1). Among the total emergency room inpatients in 2020, the number of pa-

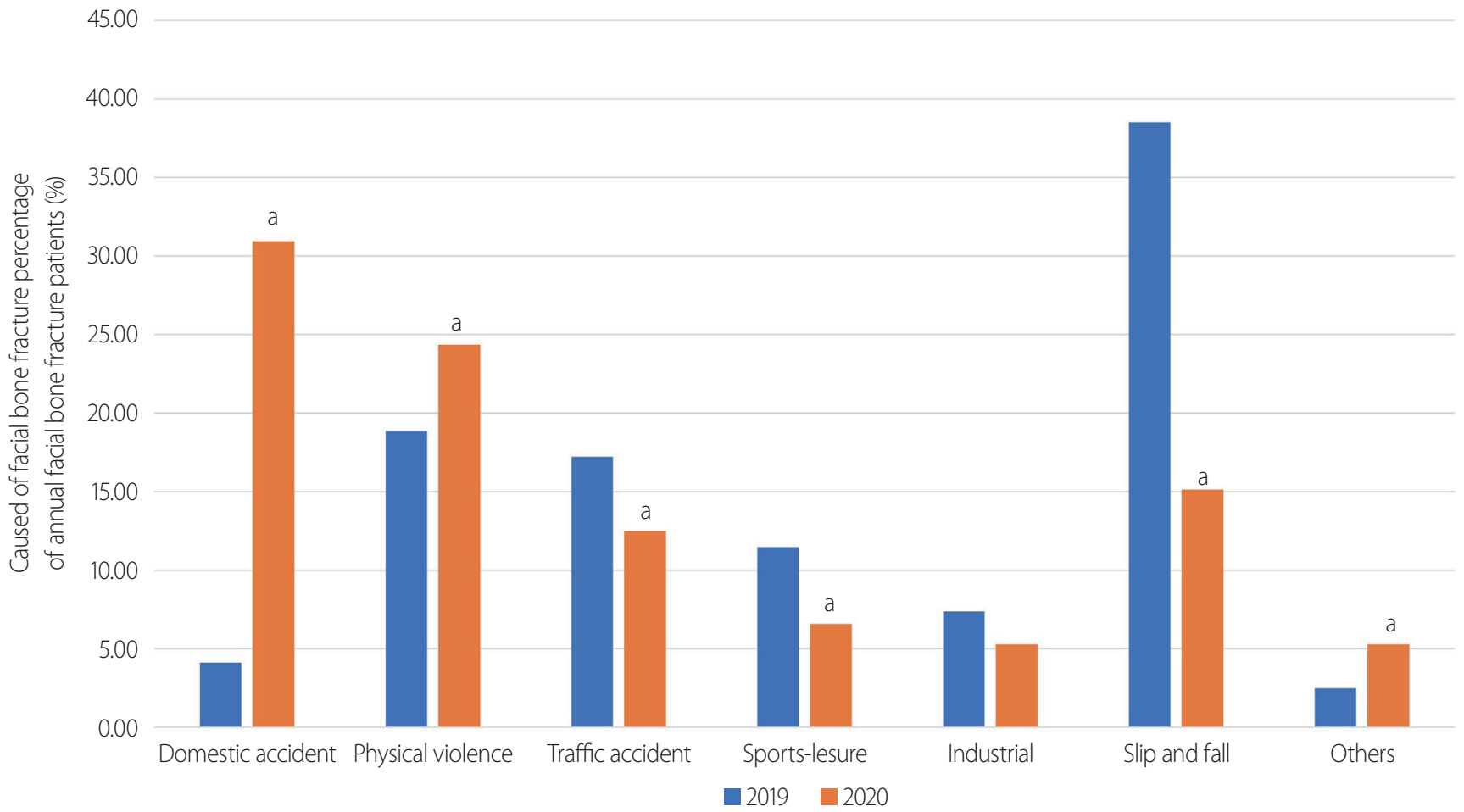

Fig. 3. The etiology of facial bone fractures in 2019 versus 2020 . ${ }^{2}$ Statitically significant $p<0.05$.

Table 3. Anatomical distribution of facial bone fractures before and during COVID-19

\begin{tabular}{|c|c|c|c|c|}
\hline & 2019 & 2020 & Difference & $p$-value \\
\hline Total & $367(100.00)$ & $344(100.00)$ & & \\
\hline Nasal bone & $219(44.79)$ & $133(26.44)$ & $-86(-39.27)$ & $<0.001^{\mathrm{a}}$ \\
\hline Frontal bone and sinus & $1(0.20)$ & $13(2.58)$ & $12(1,200.00)$ & $<0.001^{\mathrm{a}}$ \\
\hline Superior orbital rim & $1(0.20)$ & $4(0.80)$ & $3(300.00)$ & 0.374 \\
\hline Medial orbital wall & 24 (4.91) & 47 (9.34) & 23 (95.83) & $0.007^{\mathrm{a}}$ \\
\hline Inferior orbital wall & $87(17.79)$ & $107(21.27)$ & $20(22.99)$ & 0.174 \\
\hline NEO (Naso-ethmoido-orbital fracture) & $5(1.02)$ & $12(2.39)$ & $7(140.00)$ & 0.141 \\
\hline Zygomatic arch & 15 (3.07) & $11(2.19)$ & $-4(-26.67)$ & 0.431 \\
\hline Maxillary wall & $13(2.66)$ & $16(3.18)$ & $3(23.08)$ & 0.708 \\
\hline Frontozygomatic complex & $93(19.02)$ & $128(25.45)$ & $35(37.63)$ & $0.018^{a}$ \\
\hline Mandible & $31(6.34)$ & $27(5.37)$ & $-4(-12.90)$ & 0.589 \\
\hline Alveolar bone & $0(0.00)$ & $5(0.99)$ & $5(500.00)$ & $<0.001^{a}$ \\
\hline
\end{tabular}

Values are presented as number (\%).

COVID-19: coronavirus disease 2019.

aStatistically significant $p<0.05$. 
tients with facial bone fractures was compared to the 2019 trends (Table 1). In comparison with the 2019 facial bone fracture data, the number of patients decreased from March 2020, and this trend continued until December 2020. In May and November, there were recovery periods just before the second and third outbreaks. In 2019, there were 561 patients with facial bone fractures and in 2020, there were 436 . These total numbers did not show a statistically significant difference, but the monthly incidence trends for 2020 did show a significant change (Fig. 2). In 2019, from spring to winter, the incidence of fractures continued to increase. In 2020, there were three periods of decrease, in February, August, and December, corresponding to pandemic-related lockdowns.

Analysis of the causes of trauma in patients with facial bone fractures showed a statistically significant increase in domestic accidents (2019: 4.10\% vs. 2020: 30.92\%; $p<0.001$ ) (Table 2). Conversely, slip and fall events showed a statistically significant decrease in 2020 (2019: $38.52 \%$ vs. 2020 : $15.13 \%$; $p<0.001$ ) (Fig. 3). A total of 367 patients underwent facial bone fracture reduction surgery and 244 patients underwent fixation surgery. The anatomical distribution of the injuries was evaluated. The frontozygomatic complex was the anatomical area with the greatest increase in fractures in 2020 (37.64\% increase, $p=0.018$ ), followed by medial orbital wall and frontal bone fractures. Nasal bone fractures were the most common type and showed the largest decrease (-39.27\%, $p<0.001$ ) (Table 3). To analyze trauma severity, the Injury Severity Score (ISS) was used (Table 1). The number of patients with ISS scores over 15 increased from 1,094 patients in 2019 to 1,248 patients in 2020 . The severity of facial trauma was evaluated by the anatomical site involved and whether one area, two areas, or $\geq 3$ areas were

Table 4. Comparison of the anatomical complexity of facial fractures before and during COVID-19

\begin{tabular}{|c|c|c|c|c|}
\hline & 2019 & 2020 & Difference & $p$-value \\
\hline Single fracture & $272(74.11)$ & $201(58.43)$ & $-71(-26.10)$ & $<0.001^{a}$ \\
\hline Double combined fracture & $66(17.98)$ & $85(24.71)$ & $19(28.79)$ & $<0.001^{a}$ \\
\hline Over than 3 anatomical area involved fracture & $29(7.90)$ & $58(16.86)$ & $29(100.00)$ & $<0.001^{\mathrm{a}}$ \\
\hline Total & $367(100.00)$ & $344(100.00)$ & & \\
\hline
\end{tabular}

Values are presented as number (\%).

COVID-19: coronavirus disease 2019.

aStatistically significant $p<0.05$.

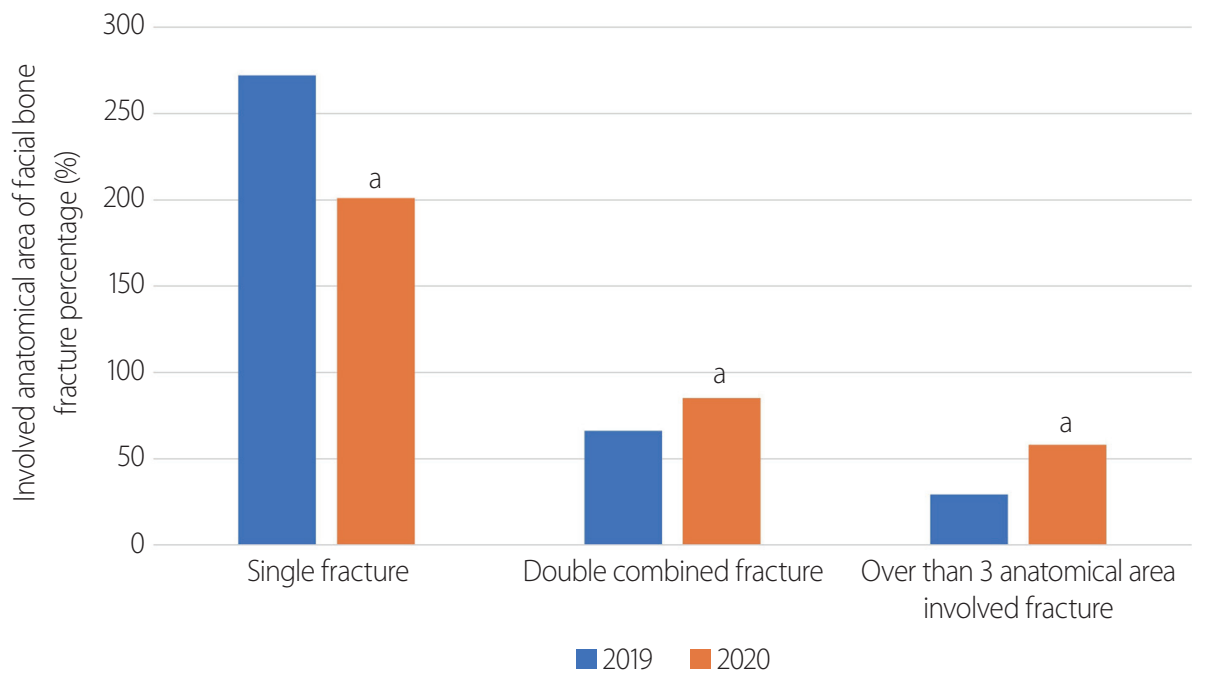

Fig. 4. Comparison of the complexity of facial bone fractures in 2019 versus 2020. aStatitically significant $p<0.05$. 
involved. All the subgroups showed statistically significant changes in 2020. The one-area group showed a significant decrease, whereas the two-area and $\geq 3$-area groups showed a significant increase in 2020 (Table 4, Fig. 4).

\section{DISCUSSION}

\section{National COVID-19 trends}

In South Korea, the government enforced strict restrictions to prevent the spread of COVID-19. Initially, the policy was implemented for a limited period; however, it had to be extended throughout 2020. The characteristics of injuries seen in the emergency department were influenced by these policies, which directly limited personal living space and impacted changes in human behavior. Decreases in certain injuries are thought to be due to a decrease in outdoor activities and sports, as a result of social distancing policies $[10,11]$. The number of patients with fractures decreased as the number of confirmed COVID-19 cases increased and government lockdowns were imposed [12].

The above pattern illustrated passive or secondary results of the pandemic-related changes in patient behavior. However, there were also active or primary patient behaviors that impacted emergency departments. Large emergency centers, such as Ajou University Hospital Level 1 Trauma Center and many of the centers in the news, were shown as overcrowded with COVID-19 patients. Thus, many people feared going to the emergency centers when their injuries were not severe. In addition, a large proportion of patients with a facial fracture opted not to undergo surgery even when indicated.

\section{Changes in facial trauma epidemiology}

The incidence patterns of patients with facial trauma were similar to the overall incidence of trauma inpatients. When the total number of emergency room patients increased, the number of facial trauma patients increased concurrently. However, during periods of decreased patient volume, such as during high-intensity social distancing, the number of overall patients decreased.

Sports-related and outdoor activity-related fractures significantly decreased. Domestic injuries were the most common causes of injury, including furniture-related slip-and-falls, injuries associated with alcohol consumption, and parental violence [13]. Even though similar injuries occurred outdoors, those injuries were classified in categories such as "slip and fall" or "other". Interpersonal violence and intimate partner violence have reportedly increased due to prolonged periods of staying at home [14]. Moreover, reports of suicide have been linked to the psychological distress attributed to the prolonged lockdown. An increase in the incidence of suicide as a result of the COVID-19 crisis has been highlighted as a major public health issue [15].

Trauma severity was also investigated. In the classification by anatomical site of injury, fracture of the frontozygomatic complex was defined as a fracture involving the zygoma and its surrounding bones [16]. The typical lines of a zygomatic complex fracture emanate superiorly from the inferior orbital fissure, along the sphenozygomatic suture to the frontozygomatic suture, where they cross the lateral orbital rim. Significantly more widespread fracture patterns imply a greater fracture severity than is associated with single-fracture patterns. In our study, an analysis of the patients who underwent facial bone fracture reduction revealed that the number of patients with three or more involved anatomical areas doubled, implying a significantly increased severity.

\section{Countermeasures for the ongoing COVID outbreak}

Several articles have analyzed the impact of the COVID-19 pandemic on surgical departments. Surgical activity declined due to infection control measures implemented during the pandemic [17-19]. Of note, facial bone reduction surgery requires an oral and gingival approach in most cases. This approach provides the best access and visibility for this surgery, despite exposure to possible virus reservoirs. Certain recommendations were taken into consideration in order to deal with the COVID-19 pandemic [20,21]. A classification of emergencies was devised in the context of the current pandemic, providing a framework for decision-making in oral and maxillofacial trauma surgery care. While measuring a patient's fracture severity, a COVID-19 risk assessment should be done concurrently, and management of cross-infection should be ongoing. Thus, in many surgical departments, par- 
ticularly in maxillofacial surgical units, non-COVID-19 patients were also managed according to the guidelines provided by national and international disease control agencies to prevent the spread of COVID-19. Specifically, single-occupancy hospital rooms were utilized, and patients remained in the same operating room and post-anesthesia recovery room. Emphasis was placed on procuring personal protective equipment and comfortable face shields and masks that did not interfere with the field of vision during surgery.

\section{Limitation}

This study had several limitations, including the inherent limitations associated with its retrospective design. Additionally, the sample size was small and the study was conducted at a single institution. This study only included patients who were evaluated by plastic, oral, and maxillofacial surgeons in the emergency room. Owing to the increased workload in the emergency room, trauma physicians may have suggested that some patients return home and may not have emphasized the need for a formal consultation with a specialized doctor. These patient numbers may have affected the final study results. Moreover, there could have been a surgeon preference regarding when patients underwent surgery, and the operation timing could not be standardized. The ISS data collected for this study were obtained from the total trauma center statistics. For future studies, we plan to trace the trends of more specific face and head ISS data. In this study, the number of involved anatomical sites of facial trauma were used to analyze trauma severity. However, within a single-center study, these variations were minimal compared to those in multicenter studies. Despite these limitations, this study is meaningful for its evaluation of how facial trauma inpatient management was affected by changes in trauma centers during the COVID-19 pandemic.

\section{CONCLUSIONS}

This study demonstrated that the incidence of facial trauma patients correlates with the number of patients presenting to the emergency department, and that facial trauma is inextricably related to multiple trauma cases.
During 2020, three large outbreaks of COVID-19 led to high-intensity social distancing practices. Domestic accidents were more common causes of injury during these periods than traffic accidents or work-related accidents seen in the previous year. Facial trauma involving multiple anatomical sites was more severe than isolated fractures.

\section{CONFLICTS OF INTEREST}

No potential conflict of interest relevant to this article was reported.

\section{INFORMED CONSENT}

This type of study does not require informed consent.

\section{REFERENCES}

1. Solomon MD, McNulty EJ, Rana JS, Leong TK, Lee C, Sung $\mathrm{SH}$, et al. The COVID-19 pandemic and the incidence of acute myocardial infarction. N Engl J Med 2020;383:691-3.

2. Kaul D. An overview of coronaviruses including the SARS-2 coronavirus-molecular biology, epidemiology and clinical implications. Current Medicine Research and Practice 2020;10:5464.

3. Chen YH, Fang CT, Huang YL. Effect of non-lockdown social distancing and testing-contact tracing during a COVID-19 outbreak in Daegu, South Korea, February to April 2020: a modeling study. Int J Infect Dis 2021;110:213-21.

4. Kim S, Jeong YD, Byun JH, Cho G, Park A, Jung JH, et al. Evaluation of COVID-19 epidemic outbreak caused by temporal contact-increase in South Korea. Int J Infect Dis 2020;96:454-7.

5. Lee Y, Kirubarajan A, Patro N, Soon MS, Doumouras AG, Hong D. Impact of hospital lockdown secondary to COVID-19 and past pandemics on surgical practice: a living rapid systematic review. Am J Surg 2021;222:67-85.

6. Adekeye EO. The pattern of fractures of the facial skeleton in Kaduna, Nigeria. A survey of 1,447 cases. Oral Surg Oral Med Oral Pathol 1980;49:491-5.

7. Adebayo ET, Ajike OS, Adekeye EO. Analysis of the pattern of maxillofacial fractures in Kaduna, Nigeria. Br J Oral Maxillofac 
Surg 2003;41:396-400.

8. Kaul RP, Sagar S, Singhal M, Kumar A, Jaipuria J, Misra M. Burden of maxillofacial trauma at level 1 trauma center. Craniomaxillofac Trauma Reconstr 2014;7:126-30.

9. Chalya PL, Mchembe M, Mabula JB, Kanumba ES, Gilyoma JM. Etiological spectrum, injury characteristics and treatment outcome of maxillofacial injuries in a Tanzanian teaching hospital. J Trauma Manag Outcomes 2011;5:7.

10. Yeo TJ. Sport and exercise during and beyond the COVID-19 pandemic. Eur J Prev Cardiol 2020;27:1239-41.

11. Evans DP. COVID-19 and violence: a research call to action. BMC Womens Health 2020;20:249.

12. Lee DW, Choi SY, Kim JW, Kwon TG, Lee ST. The impact of COVID-19 on the injury pattern for maxillofacial fracture in Daegu city, South Korea. Maxillofac Plast Reconstr Surg 2021;43:35.

13. Krishnakumar A, Verma S. Understanding domestic violence in India during COVID-19: a routine activity approach. Asian J Criminol 2021 Mar 10. doi: 10.1007/s11417-020-09340-1 [Epub ahead of print].

14. Kim K. Impacts of COVID-19 on transportation: summary and synthesis of interdisciplinary research. Transp Res Interdiscip Perspect 2021 Jan 18. doi: 10.1016/j.trip.2021.100305 [Epub ahead of print].
15. McIntyre RS, Lee Y. Preventing suicide in the context of the COVID-19 pandemic. World Psychiatry 2020;19:250-1.

16. Chakranarayan A, Thapliyal GK, Sinha R, Suresh MP. Efficacy of two point rigid internal fixation in the management of zygomatic complex fracture. J Maxillofac Oral Surg 2009;8:265-9.

17. Randelli PS, Compagnoni R. Management of orthopaedic and traumatology patients during the coronavirus disease (COVID-19) pandemic in northern Italy. Knee Surg Sports Traumatol Arthrosc 2020;28:1683-9.

18. Wong JSH, Cheung KMC. Impact of COVID-19 on orthopaedic and trauma service: an epidemiological study. J Bone Joint Surg Am 2020;102:e80.

19. Coccolini F, Perrone G, Chiarugi M, Di Marzo F, Ansaloni L, Scandroglio I, et al. Surgery in COVID-19 patients: operational directives. World J Emerg Surg 2020;15:25.

20. de Boutray M, Kün-Darbois JD, Sigaux N, Lutz JC, Veyssiere A, Sesque A, et al. Impact of the COVID-19 lockdown on the epidemiology of maxillofacial trauma activity: a French multicentre comparative study. Int J Oral Maxillofac Surg 2021;50:750-5.

21. Bertin H, Koudougou C, Marion F, Corre P, Deransy R. Re: toward a consensus view in the management of acute facial injuries during the COVID-19 pandemic. Br J Oral Maxillofac Surg 2020;58:731-2. 